\title{
EL VIAJE A QUILLAGUA DE RICARDO LATCHAM EN 1932: NOTAS Y REFLEXIONES DESDE UN MANUSCRITO INÉDITO
}

\author{
Francisco Garrido y Benjamín Ballester ${ }^{2}$ \\ ${ }^{1}$ Museo Nacional de Historia Natural, Casilla 787, Santiago de Chile, francisco.garrido@mnhn.gob.cl \\ ${ }^{2}$ Museo Chileno de Arte Precolombino, Bandera 361, Santiago de Chile, benjamínballesterr@gmail.com
}

\section{RESUMEN}

Este artículo trae a la luz un manuscrito inédito del arqueólogo Ricardo Latcham, proveyendo además de una descripción del mismo y de un contexto contemporáneo sobre las investigaciones arqueológicas realizadas en el oasis de Quillagua, norte de Chile. Latcham excavó diversos cementerios en esta localidad el año 1932, los cuales abarcaban distintos períodos prehispánicos y fueron en gran medida la base para su posterior libro sobre arqueología atacameña. Dichas colecciones están depositadas en el Museo Nacional de Historia Natural, institución de la cual Latcham fue su director.

El manuscrito presentado aquí es una versión extendida y más completa del artículo Notas preliminares de un viaje arqueológico a Quillagua (Latcham 1933), el cual describe en detalle los contextos excavados y los materiales obtenidos de varias de las sepulturas de Quillagua. Esta es una información única y relevante para dar nuevo significado e interpretación a los contextos arqueológicos excavados por Latcham, una fuente primaria invaluable para investigaciones futuras.

Palabras clave: Latcham, Atacama, Arqueología, Quillagua, MNHN.

\section{ABSTRACT}

Ricardo Latcham's journey to Quillagua in 1932: notes and reflections from an unpublished manuscript. This paper highlights an unpublished manuscript by the archaeologist Richard Latcham, by describing its contents and providing an overview of the state of archaeological research carried out in the Quillagua oasis, northern Chile.

Latcham excavated several burials in Quillagua in 1932, which belonged to various prehispanic periods and formed the basis of his book about Atacamenian archaeology. These archaeological collections are deposited in the National Natural History Museum (Chile), where Latcham served as its director.

The manuscript presented here is an extended version of the article Notas preliminares de un viaje arqueológico a Quillagua (Latcham 1933), describing in detail the excavated contexts and the arcaheological materials obtained from each burial in Quillagua. This unique and relevant information allows for a new interpretation of the archaeological contexts excavated by Latcham, as an important primary source for future research.

Keywords: Latcham, Atacama, Archaeology, Quillagua, MNHN.

\section{INTRODUCCIÓN}

El trabajo de Ricardo Latcham es de enorme riqueza y ha servido hasta el día de hoy como cimiento de buena parte de las investigaciones arqueológicas y antropológicas, tanto en las localidades específicas que él estudio, como a largo de todo el territorio nacional. Sin embargo, es muy poco lo que se sabe acerca del detalle de las intervenciones en los sitios arqueológicos que excavó a lo largo de Chile. Es sus publicaciones son habituales las referencias generales y comparativas, planteadas desde una arqueología a 
escala regional, lo cual hace muy complejo el re-estudio de las colecciones arqueológicas y los sitios que él trabajó casi un siglo atrás.

Los pormenores de la ubicación exacta de los yacimientos, los contextos funerarios, el número de tumbas y la proveniencia de ciertos objetos útiles para entender sus excavaciones, son testimonios que están en su gran mayoría ausentes en los artículos y libros que Latcham publicó. Este vacío no se debe a la falta de registro arqueológico en su investigación, sino más bien a que tales aspectos no fueron considerados pertinentes dentro del enfoque de sus publicaciones. En sus artículos y libros primaba más bien lo interpretativo y comparativo por sobre lo técnico y específico. En dicha época recién se estaban formando los marcos cronológico-culturales del pasado prehispánico chileno, razón por la cual se privilegiaban las generalizaciones amplias de estilos artefactuales y su dispersión geográfica, más que el detalle de su procedencia.

En la actualidad, frente a otras inquietudes y procedimientos, la información de los sitios arqueológicos excavados por Latcham es de gran relevancia para la investigación y de ahí también que sea crucial el trabajo de archivo. Y ha sido en tal búsqueda que se ha logrado identificar en el Archivo Histórico Administrativo del Museo Nacional de Historia Natural (MNHN) de Santiago, un documento que presenta una versión previa y ampliada del artículo titulado Notas preliminares de un viaje arqueológico a Quillagua (1933), el cual narra sus descubrimientos realizados el mes de noviembre del año 1932 como parte de sus exploraciones a la zona del Loa en búsqueda de sitios arqueológicos.

Además de dicho artículo publicado en la Revista Chilena de Historia Natural, son habituales las referencias a Quillagua en su célebre libro Arqueología de la Región Atacameña (Latcham 1938). En tal obra se exponen diversas categorías de artefactos agrupados por materialidad, pero no se describen los yacimientos ni sus contextos, a diferencia de la forma en como lo hace en el manuscrito en cuestión. Aquí yace probablemente su mayor valor, pues describe la ubicación de los sitios, en algunos casos el inventario tumba por tumba de los materiales recuperados, y se identifica el cementerio de proveniencia, su asociación contextual, los rasgos fúnebres y arquitectónicos, además de comentar la posible filiación cultural de ciertas piezas y de los cuerpos humanos.

\section{SÍNTESIS DE LA INFORMACIÓN CONTENIDA EN EL DOCUMENTO}

En cuanto al tema arqueológico, el documento de Latcham relata el abundante saqueo de sitios precolombinos que ya para esa época había sufrido la zona de Quillagua, fomentando un mercado de piezas vendidas en los puertos salitreros. Los cementerios excavados por él corresponden a los siguientes (Figura 1):

Cementerio atacameño de Quillagua. Se ubica en una faja angosta de tierra arenosa entre el pie de cerro y los campos de cultivo del rio Loa. Se excavaron 9 tumbas de adultos y párvulos, incluyendo en su cultura material textiles decorados, gorros, sandalias, cerámica, maíz, puntas de proyectil y torteras, entre otros elementos.

Cementerio de Ancachi (02Qui75) ${ }^{1}$. Ubicado en una planicie a 25 metros sobre el nivel del rio, a $10 \mathrm{~km}$ al norte de Quillagua. Se excavaron 20 sepulturas previamente removidas por saqueadores. Se obtuvieron 10 cuerpos momificados de adultos, 4 de párvulos y un camélido, pero, sin embargo, solo fueron sacados del sitio 3 cuerpos de adulto y un niño. De las sepulturas se obtuvo cestería, maíz y quinoa.

\footnotetext{
${ }^{1 /}$ Códigos de sitio en base a Gallardo et al. 1993a, 1993 b.
} 


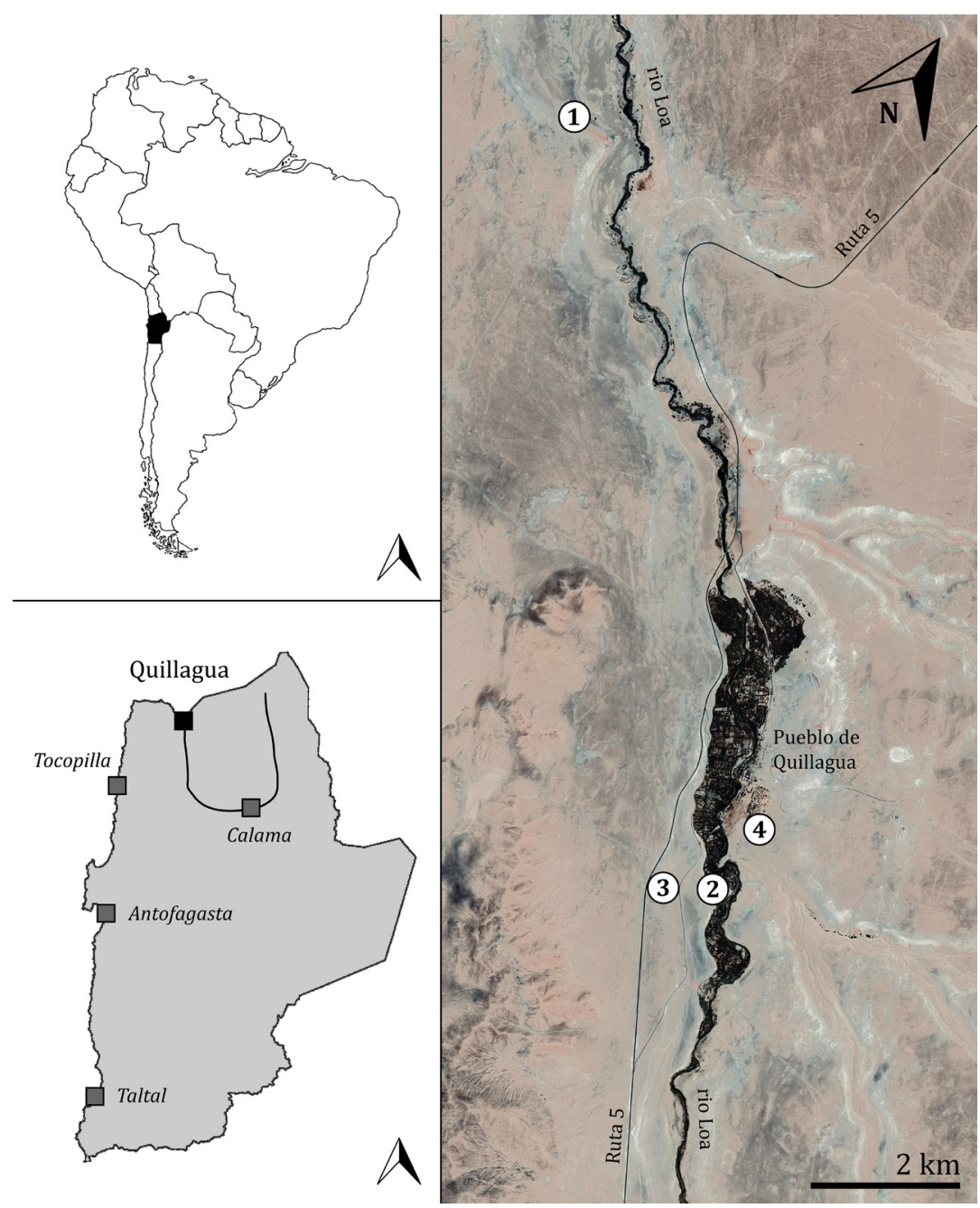

Figura 1: mapa con la ubicación de los sitios arqueológicos del valle de Quillagua mencionados en el texto: (1) cementerio de Ancachi (02Qui75); (2) aldea La Capilla (02Qui04); (3) cementerio poniente (02Qui03); (4) cementerio oriente (02Qui01).

Cementerio poniente (02Qui03). Se ubica en el camino de Quillagua a la costa. Consiste en sepulturas superficiales, con cuerpos envueltos en textiles. Se registraron en asociación puntas de proyectil, cerámica doméstica, maíz, gorros de piel y cestería.

Cementerio oriente (02Qui01). Se ubica en la cima de un cerro al sureste de la estación del ferrocarril. Latcham excavó una veintena de tumbas a una profundidad mayor a 2 metros. De los materiales asociados a las sepulturas obtuvo textiles decorados, gorros, cestería, cerámica, tabletas de madera y tubos inhalatorios, cajitas de colorantes, punzones y espátulas de hueso, algunos artefactos de cobre, torteras, un carcaj con flechas, una coraza de cuero, maíz, restos de pescado y calabazas.

Fuera de los cementerios, Latcham también describe un "Gentilar" o poblado prehispánico ubicado a 1 kilómetro al sur del pueblo de Quillagua, en una extensión de 150 por 50 metros. Consistía en una serie de recintos pircados aglutinados con una altura que llegaba a un metro. 
En la parte final del documento, Latcham pone algunas anotaciones de vocabulario atacameño, y finaliza con un texto no relacionado al anterior y que versa sobre las excavaciones del sitio El Olivar de Francisco Cornely. En tal sección reflexiona sobre la diferencia de aquellos hallazgos con lo atacameño, hablando de que serían "Diaguita" y "Chincha Diaguita".

\section{LOS RESULTADOS DE LAINVESTIGACIÓNY LOS NUEVOS TRABAJOS ENQUILLAGUA}

De los materiales recuperados por Latcham en dicha campaña, él menciona que "trajimos cuarenta cajones para el museo, que contenían cincuenta momias y más de seiscientos objetos hallados en las sepulturas, lo que representa, en general, el ajuar funerario completo de ese pueblo y nos ayuda a formar una idea bastante aproximada acerca de su vida material" (Latcham 1933:134). Lo ingresado en el inventario del MNHN en 1932 se encuentra detallado en la tabla 1.

En su interpretación basada en los esquemas de Max Uhle, Latcham clasificó los cementerios identificados en Quillagua como atacameño indígena y chincha atacameño. Posteriormente, él atribuyó al cementerio de Ancachi a la época de Tiahuanaco (Latcham 1938). Las publicaciones de Latcham y las colecciones museográficas de Quillagua fueron relevantes para continuar la investigación en dicha zona hasta el presente, tanto a partir de nuevas prospecciones en el valle, como también por medio de excavaciones de sitios, colecta de material superficial y análisis de objetos de museos.

\begin{tabular}{|c|c|}
\hline Categoría de artefacto & $\mathbf{N}$ \\
\hline Artefactos de madera & 169 \\
\hline Textiles & 142 \\
\hline Restos humanos & 68 \\
\hline Fibras vegetales & 63 \\
\hline Artefactos de cuero & 60 \\
\hline Artefactos líticos & 55 \\
\hline Alfarería & 33 \\
\hline Artefactos óseos & 33 \\
\hline Fibras textiles & 16 \\
\hline Metales & 10 \\
\hline Malacológico & 9 \\
\hline Arqueofauna & 8 \\
\hline Plumaria & 3 \\
\hline Semillas & 1 \\
\hline Restos vegetales & 1 \\
\hline Total & 671 \\
\hline
\end{tabular}

Tabla 1: restos arqueológicos recuperados por Ricardo Latcham en Quillagua inventariados en 1932 en el MNHN. 
El gentilar o poblado prehispánico al que refiere Latcham probablemente corresponde a la aldea de La Capilla (02Qui04), un importante sitio arqueológico que fue visitado décadas más tarde por Bernardo Toloza, quien recuperó una cantidad importante de material arqueológico depositado hoy en el Museo de Antofagasta (Ballester 2021a). Tras una visita y algunas colectas de Lautaro Núñez (1965a, 1965b), fueron sus alumnos Miguel Cervellino y Francisco Téllez (1980), quienes excavaron con mayor detención el sitio, cuyo fechado radiocarbónico (Núñez 1976) y materiales lo sitúan en el Período Intermedio Tardío y Tardío (1100-500 AP).

Estudios posteriores de Francisco Gallardo y su equipo (1993a, 1993b; Strange 1995), y más tarde por Carolina Agüero y colaboradores (Agüero et al. 1995, 2001, 2006; Carrasco 2001, 2002; Carrasco et al. 2003), permitieron descubrir nuevos sitios, refinar la cronología, comprender mejor los patrones de asentamiento y caracterizar de manera más precisa la cultura material precolombina del valle. Más tarde, continuaron las investigaciones arqueológicas en el valle de la mano de los/as mismos/as y de nuevos/as investigadores/as (p.e. Gallardo 2019; Gallardo y Odone 2019; García et al. 2012; Méndez-Quiroz y Vidal 2010; Pestle et al. 2019; Pinder et al. 2019; Santana et al. 2015).

Junto a estas iniciativas ha sido posible también profundizar en los estudios de ciertas materialidades y clases de objetos. Destacan entre ellos los trabajos orientados a la descripción y definición tipológica de las secuencias cerámicas locales del Formativo, en donde predominan los tipos Loa Café Alisado y Quillagua Tarapacá Café Amarillento, siendo este oasis una bisagra cultural entre los territorios del norte y los del sur (p.e. Ayala 2001; Uribe y Ayala 2004).

Las antiguas y nuevas colecciones textiles de Quillagua han servido también de insumo para cuantiosas investigaciones, con especial énfasis en el tema de la identidad y del carácter de frontera del valle desde el período Formativo y hasta el Período Intermedio Tardío (p.e. Agüero 1998, 2015; Agüero y Cases 2004; Agüero et al. 1997; 1999; Cases 2003, 2007; Correa 1998). En algunos casos el estudio de las vestimentas se ha correlacionado incluso con las expresiones del arte rupestre para problematizar el tema de las relaciones identitarias (Cases y Montt 2013; Pimentel y Montt 2008).

Destacan también los estudios enfocados en los restos bioantropológicos, especialmente aquellos sobre la dieta, proveniencia, movilidad y filiación cultural de los individuos a partir de los análisis de isótopos estables (Pestle et al. 2019; Pinder et al. 2019; Santana et al. 2015). Resultados que han mostrado que Quillagua estuvo ocupado por poblaciones culturalmente diferentes e incluso de orígenes diversos, al menos desde el período Formativo y de manera más importante para el Período Intermedio Tardío.

Por todo ello, Quillagua es concebido hoy como un espacio de interdigitación étnica en la cual coexistieron grupos de distinta filiación cultural; durante el período Formativo por colectivos ligados al mundo litoral, tarapaqueño y loíno, y en el Período Intermedio Tardío por grupos vinculados a Pica-Tarapacá y Atacama, cuyas divisiones y relaciones interculturales también se manifestaron en épocas posteriores al contacto europeo (Gallardo y Odone 2019; Gallardo et al. 2019; Odone 1995, 2017).

En todas estas investigaciones y publicaciones se reconoce un claro legado del trabajo inicial realizado por Ricardo Latcham. Es por ello que hemos decidido publicar este manuscrito inédito, esperando contribuir a los futuros estudios sobre este oasis del desierto de Atacama. En efecto, en instancias previas el MNHN de Santiago ya había hecho el gesto de publicar manuscritos inéditos de Ricardo Latcham como una manera de continuar su legado luego de su fallecimiento y de socializar el conocimiento que, por distintas razones, no pudo llegar al público tras su escritura (p.e. Latcham 1969). Es por ello que presentamos la transcripción íntegra del documento. 


\section{ACLARACIONES A LA TRANSCRIPCIÓN DEL MANUSCRITO}

El nuevo documento a que nos referimos posee la sigla AHA 461-146 y se compone de 14 páginas de texto mecanografiado, acompañado por algunas ilustraciones de artefactos arqueológicos y anotaciones hechas a mano con lápiz grafito. El texto se titula Viaje a Quillagua.- Nov. 22 de 1932, MS. de Ricardo E. Latcham.

El documento fue transcrito íntegramente respetando su escritura y estructura original.. En cursiva se señalan las fechas y días de los eventos relatados. Entre paréntesis cuadrados, por su parte, hemos incorporado información sobre el manuscrito que no se encuentra escrita en su versión original, como insumo para el/la lector/a, tales como el número de página, referencia a nuevas figuras y fragmentos faltantes o inconclusos.

Así mismo, hemos incluido una serie de notas al pie para aclarar temas relevantes del manuscrito, señalar la ubicación de localidades y sitios, explicar conceptos, entregar información complementaria y actualizar los datos según el estado actual de conocimiento arqueológico sobre dichos temas.

Finalmente, con tal de enriquecer aún más el contenido del manuscrito hemos incorporado fotografías de algunos de los objetos recuperados por Ricardo Latcham en sus intervenciones de sitios del valle de Quillagua. Dichas piezas fueron buscadas en los inventarios y colecciones del MNHN, en función de la descripción y rasgos materiales referidos en el texto.

\section{VIAJE A QUILLAGUA}

Noviembre 22 de 1932

\section{[Página 1].}

Quillagua es una pequeña aldea situada en el extremo sur de la provincia de Tarapacá, sobre el rio Loa y a unos 70 a $80 \mathrm{~km}$ en línea recta de la costa [Figura 1].

El valle de Quillagua forma parte de un oasis, en medio del desierto, que se extiende en toda dirección. Es de poca extensión, pero los terrenos son muy fértiles, aunque no se producen en ellas más que la alfalfa y el maíz. Las aguas salobres del Loa impiden los demás cultivos. Un análisis de dichas aguas ha dejado constancia de que, en tiempos normales, cuando no hay crece del río, contienen $71 / 2 \%$ de cloruro de sodio. Esto se debe a la unión con el Loa, a la altura de Chiu Chiu, del Salado. Este último no recibe drenaje del Salar de Atacama, de donde obtiene su salinidad.

El valle de Quillagua está bastante poblado de algarrobos y chañares con uno que otro tamarugo.

La alfalfa que se cultiva en el valle es de la más hermosa y vigorosa del país y es completamente limpia de malezas ${ }^{2}$, si exceptuamos la acelga que crece espontáneamente en los terrenos de cultivo aunque es planta extranjera en su origen.

\footnotetext{
${ }^{2 /}$ Para una historia profunda de la alfalfa en Quillagua y en todo el desierto de Atacama ver Carmona 2018.
} 
Las únicas aves que se encuentran actualmente en el valle son: el penco, el tucúquere, el chuncho, el pidén, la taguá, ocasionalmente patos, la loica, el chincol, el chercán y el cernícalo.

Animal no hay más que una especie de ratón de campo.

Insectos con la excepción de las moscas, mosquitos y zancudos son escasos aunque dicen que en ciertas épocas del año abundan las vinchucas aunque oportunamente no las vimos. En el río se hallan libélulas. Lagartos hay dos o tres especies, una de las cuales llamada samandrija es casi cristalina y transparente. El río abunda en pejerreyes y camarones.

En la pampa de tamarugal, a pocos kilómetros de Quillagua se encuentran bosques de algarrobas enterrados o sepultados bajo las arenas. Estos se llaman minas de leña y son explotados por los vecinos para la fabricación de carbón de magnífica clase, que se vende en las oficinas salitreras y en los puertos de Antofagasta, Tocopilla e Iquique, donde está muy apreciado por sus altas calorías.

Los bosques que hay actualmente en el valle de Quillagua son principalmente de algarrobos aunque hay chañares y unos pocos tamarugos.

[Página 2]

El único árbol exótico que se encuentra en el valle es el molle o pimiento, importado del Perú.

En ambos lados del río en las tierras juntas al pie del cerro, existían, en varios kilómetros de extensión, un enorme número de sepulturas indígenas. Casi todas ellas han sido expoliadas por los buscadores de tesoro y los curiosos ${ }^{3}$. Han hecho excavaciones ahí también, varias expediciones europeas, que han llevado los restos de numerosísimos cementerios ${ }^{4}$. Sin embargo, parece que la inmensa mayoría de las tumbas se han abierto por simple curiosidad o para sacar objetos de greda o cacharros que han sido vendidos a los extranjeros de los puertos de Antofagasta y Tocopilla o de las salitreras vecinas ${ }^{5}$. Por consiguiente es difícil encontrar sepulturas intactas hoy, y menos aún cementerios sin revolver.

El vandalaje ha sido completo como se demuestra por la enorme cantidad de huesos humanos, restos de momias y trozos de tejidos desparramados por las faldas de los cerros.

\footnotetext{
${ }^{3 /}$ Muy poco se conoce acerca de la historia de las excavaciones e intervenciones de sitios arqueológicos en Quillagua por parte de coleccionistas de piezas precolombinas. Existe registro, sin embargo, de coleccionistas que poseían importantes colecciones del valle, tal es el caso de Galvarino Ponce y de Aníbal Echeverría y Reyes, ambos de la ciudad de Antofagasta (Ballester 2021b).

${ }^{4 /}$ Entre las colecciones de piezas arqueológicas de Quillagua que se han registrado en museos europeos destacan las de Otto Aichel en el museo del Schloss Gottorf de la ciudad de Schleswig en Alemania (Aichel 1932), del señor Gutzschebauch en el Museum am Rothenbaum - Kulturen und Künste der Welt de Hamburgo en Alemania (Ballester et al. 2019a), de Daniel Diehl en el Staatliche Museen de Berlin en Alemania (Diehl 1904), de José Moldes en la Universidad de Oviedo de España (de la Barra 1909) y del señor Jones en el Pitt Rivers Museum de Oxford en Inglaterra (Pusch 1988).

${ }^{5}$ Uno de los mayores coleccionistas y excavadores de tumbas del puerto de Tocopilla fue Luis Vergara Flores, quien años antes de las intervenciones de Latcham ya había excavado y publicado varios artículos relativos a los cráneos y el arte rupestre de Quillagua (Vergara 1897, 1901, 1902, 1905; entre otros). Sus trabajos sobre craneometría son especialmente importantes, pues en ellos debatió junto a Francisco Fonck $(1911,1912)$ y el mismísimo Ricardo Latcham $(1910,1912)$. Esto quiere decir que Latcham antes de realizar su viaje a Quillagua ya conocía bien el valle y sus restos arqueológicos gracias al trabajo del doctor Vergara Flores en el lugar.
} 
Los cementerios indígenas son llamados gentilares y los antiguos indios gentiles por los actuales pobladores y aún existen individuos que profesionalmente de dedican a catear y explotar estos gentilares.

Las sepulturas de Quillagua se encuentran casi exclusivamente en una faja muy angosta de tierra arenosa, pegada al pie de los cerros y entre estos y los terrenos de cultivo que orillan el río Loa. No han podido utilizar las faldas de los cerros como en otras partes porque están formadas de capas endurecidas y sobrepuestas de yeso y arenisca.

También hay un cementerio bastante extenso en una explanada sobre un espolón saliente del cerro, un poco al S.E. de la estación de FF.CC. Allí encontramos algunas sepulturas sin remover aún cuando en su mayoría han sido revueltas y saqueadas.

Las sepulturas de hallan en forma de pozo, con cavidad lateral al fondo y tienen un promedio de 2 mts. y más de profundidad debajo de una capa de yeso endurecido y convertido en tosca. Debajo de esta capa se halla otra costra de arena apretada la que es fácil de remover. En dicha capa de arena se hallan las momias. En este cementerio los cadáveres se hallan mejor condicionados, envueltos en tejidos y formando atados mortuorios. Se nota una mayor cultura, el número de artefactos aumenta considerablemente y los tejidos son especialmente finos y de hermosos collares y dibujos. Por los tejidos

\section{[Página 3]}

los gorros de tela aterciopelados, los instrumentos de madera, etc. se cree que esta etapa cultural corresponde a la que Uhle denominó Período Atacameño.

\section{Cementerio Atacameño Indígena.}

\section{Sepulturas}

$\mathrm{N}^{\circ} 1$. Tapada de cañas (sorona) y junquillo y carrizo (cortadera) formadas en esterilla, con uno que otro palo de algarrobo para sostenerla.

Esta sepultura tenía una profundidad de $1 \mathrm{mt}$ por unos 0.80 de diámetro. El cadáver estaba originalmente envuelto primero en un tejido y después en un cuero de lobo marino, de los cuales se encontraban solamente pedazos podridos. Quedaba solamente el esqueleto, el que sacamos íntegro. Dentro de la caja torácica encontré una grande punta de flecha con pedúnculo, que puede haber sido la causa de la muerte. La sepultura no dio otra cosa. El cráneo de esta momia era deformado. La deformación era levantada, pero de forma oblicua parecido a algunos que encontré años atrás en Calama ${ }^{6}$.

$\mathrm{N}^{\circ} 2$. Sepultura de mayores pretensiones $2 \mathrm{mt}$. de profundidad, 0.80 ancho; enteramente cubierta de palos de sorona entrelazados con grueso hilo de lana. De esta sepultura, además del cadáver se sacó un gorro cilíndrico, hecho en forma de canasto de tejido espiral, con hermosos dibujos en colores; un platillo y dos cantaritos de greda, un mango de adzuela [sic.], un tubo de caña adornado con amarras de lana de colores, una concha de [ilegible] quebrado, una punta de flecha de cuarzo cristalina fijada en el asta, pedazos de la tela y de los cordeles con que se había envuelto el cadáver, un gancho de madera para aparejos de llamas, con los cordeles sujetos en su lugar, muchas corontas de maíz, 1 punta de flecha de pedernal sin pedúnculo.

\footnotetext{
${ }^{6 /}$ Las excavaciones en Calama de Ricardo Latcham se concentraron en el cementerio del Regimiento Chorrillos, cuyos contextos y materiales se describen de manera fragmentada en Latcham 1938.
} 
Encima a $50 \mathrm{cmts}$ de profundidad se encontró el cadáver de un párvulo envuelto completamente en un tejido, con las chalalas sujetas a la cintura con un cordelito de lana.

Parece haberse enterrado después bolsas tejidas llenas de una sustancia que no se ha podido determinar. Cráneos con deformación oblicua.

$\mathrm{N}^{\circ}$ 3. Al lado oriente de la línea, $10 \mathrm{mts}$ de $\mathrm{N}^{\circ} 2$ se repitió el caso de la $\mathrm{N}^{\circ} 1$. No había más que el cadáver envuelto en un tejido comple-

[Página 4]

tamente podrido sin ningún otro objeto que unas corontas de maíz. Profundidad $1 \mathrm{mt}$.

Cráneo deformación oblicua.

$\mathrm{N}^{\circ} 4$. Id id

Cráneo normal.

$\mathrm{N}^{\circ}$ 5. (Al lado de $\mathrm{N}^{\circ}$ )

Tapado igual al ํ2, 2 mts de profundidad. Cadáver sin tejido. Esqueleto sin carne. Se encontró en esta sepultura una fuente de greda, quebrada, 3 puntas de flecha, una pesa para lienza de pescar, una concha de choro y varios huesos de pescado sin contar numerosas corontas de maíz sin grano, un gorro compuesto de cuero de animal y piel de ave.

Cráneo normal.

$\mathrm{N}^{\circ} 6$ (Al lado del $\mathrm{N}^{\circ} 5$, a 3 mts distancia)

Profundidad $2 \mathrm{mts}$. Tapada de la misma forma que el $\mathrm{N}^{\circ} 5$. Parece haber sido un entierro secundario [sic] por encontrarse el cadáver sin tejidos, ni ningún otro objeto y de hallarse atravesado en el hoyo. Era de un viejo y en la quijada inferior le falta gran parte de la dentadura.

Cabeza de ratón.

Gorro de lana blanca. Cráneo deformación oblicua.

$\mathrm{N}^{\circ} 7$ (Otro lado de la línea $4 \mathrm{mts}$ del N³)

$0.80 \mathrm{mts}$. profundidad. Esqueleto de un niño, restos del tejido del envoltorio, 1 huso con tortera de madera, flecos de lana, chalalas, canastito de palos y tejido de lana. Cráneo deformación levantada oblicua.

$\mathrm{N}^{\circ} 8$. Al lado de $\mathrm{N}^{\circ} 6$.

Esqueleto de niño sin tejido ni ningún otro objeto.

Cráneo con deformación levantada oblicua. 
$\mathrm{N}^{\circ}$ 9. Otro lado de línea, $5 \mathrm{mts}$ de $\mathrm{N}^{\circ} 7$. Profundidad $80 \mathrm{cms}$. Envoltorio podrido. Esqueleto, 2 sandalias, 1 fuente de greda, 1 tortera, cráneo normal.

\section{[Página 5]}

$\mathrm{N}^{\circ} 10$. Sepultura al lado del camino a Tocopilla, 30 metros del recodo que pasa por medio de las chacras, hasta el vado de la población.

En esta sepultura se hallaron 3 cadáveres y un párvulo desnudo. Sólo una de las momias se pudo sacar en más o menos buenas condiciones, en parte envuelto en el tejido. Los otros dos se despedazaron al tocarlos y los envoltorios estaban en tan mal estado y tan podridos que salieron en fragmentos. No se halló ningún artefacto u otra cosa. Por todo el largo de este camino por muchos centenares de metros se hallaban dos interminables hileras de sepulturas, pero han sido todas abiertas y las momias destrozadas o llevadas. Las dos hileras están al lado del camino, a unos $5 \mathrm{mts}$. de los cierres de las chacras. Parece que los indios no enterraban a los muertos en los terrenos de cultivo sino en la arena o tierra árida al pie del cerro. Dos de los cráneos de este entierro tenían deformación levantada oblicua y el otro era normal.

\section{Miércoles 9 de Noviembre}

Fui con una cuadrilla de 6 hombres y 3 mulas a Ancachi situada en una planicie unos $25 \mathrm{mts}$ sobre el nivel del río, a unos $10 \mathrm{~km}$ al norte de Quillagua [Figura 1]. Allí tenía noticias de otro gentilar o cementerio, pero como en Quillagua había sido bastante explotado. Abrimos más de 20 sepulturas pero con relativa mala suerte, porque habían sido saqueadas en su mayor parte y rellenadas de nuevo ${ }^{7}$. No obstante pudimos sacar diez momias adultos y cuatro de párvulos o guaguas. También se halló en una de las sepulturas, una llama momificada que se sacó en pedazos.

Junto con las momias se hallaron varios platos de cestería todos de tamaño chico y dentro de algunas semillas de maíz [Figura 2] y de quínoa. A $50 \mathrm{~cm}$ de profundidad todo el llano se halla cubierto de una capa de tertel o tosca de unos $30 \mathrm{~cm}$ de espesor. Arriba y abajo se halla arena mezclada con greda. Para hacer las sepulturas han perforado la capa de tosca de esta han hecho el entierro. Se abría un pozo, raras veces máximo de $80 \mathrm{~cm}$ de diámetro en forma rudamente circular y a veces con un sacado al pie, por un lado en forma de bota. En tales casos se enterraba al cadáver en el hueco lateral.

Solamente llevamos tres momias de adultos y una de un niño pequeño. Tres de las momias sacadas tenían los cráneos deformados por constricción, del tipo llamado aymará. De los restantes uno era deformado levantado oblicuo y los otros normales. Entre los restos desparramados en los contornos del cementerio habían una veinte-

\section{[Página 6]}

na de cráneos deformados por constricción y otros tantos normales, todos sin embargo más o menos destrozados.

\footnotetext{
${ }^{7 /}$ Este gentilar corresponde a un cementerio de túmulos que ha sido recientemente investigado por el equipo de Francisco Gallardo, con fechados radiocarbónicos que corroboran que su cronología sería del período Formativo y que los individuos ahí enterrados estarían ligados a nivel cultural y de modo de vida con el mundo litoral (Pestle et al. 2019; Pinder et al. 2019).
} 


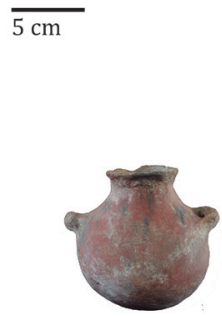

A

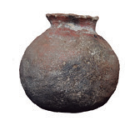

D

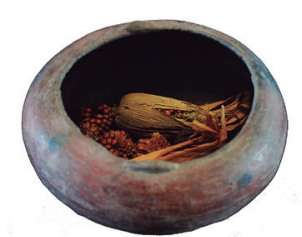

G

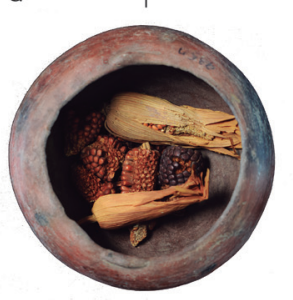

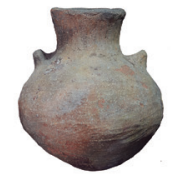

$\mathrm{B}$

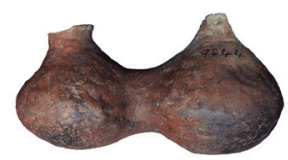

E

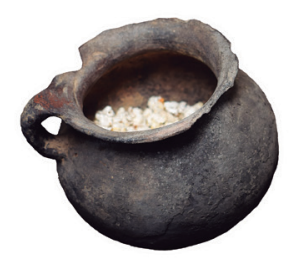

$\mathrm{H}$

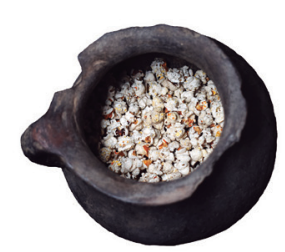

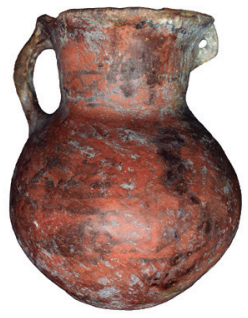

C

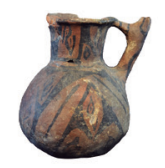

$\mathrm{F}$

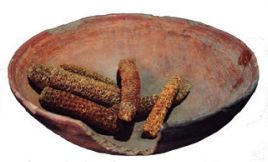

I

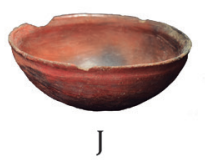

Figura 2: Contenedores cerámicos de Quillagua de la colección Latcham del MNHN: (A) vasija de dos asas decorada $\left(\mathrm{N}^{\circ}\right.$ Inv. 9343); (B) vasija con mamelones ( $\mathrm{N}^{\circ}$ Inv. 9341); (C) jaro decorado con líneas negras sobre fondo rojo $\left(\mathrm{N}^{\circ}\right.$ Inv. 9354); (D) pequeña vasija que contiene pululos o maíz reventado ( $\mathrm{N}^{\circ}$ Inv. 9358); (E) vasija doble $\left(\mathrm{N}^{\circ}\right.$ Inv. 9344); (F) jarro decorado con figuras de color negro ( $\mathrm{N}^{\circ}$ Inv. 9353); (G) puco cerámico con mazorcas de maíz en su interior $\left(\mathrm{N}^{\circ}\right.$ Inv. 9350); (H) vasija repleta de pululo o maíz reventado en su interior ( $\mathrm{N}^{\circ}$ Inv. 9362); (I) escudilla que contiene mazorcas de maíz ( $\mathrm{N}^{\circ}$ Inv. 9349); (J) escudilla ( $\mathrm{N}^{\circ}$ Inv. 9347). .

\section{Cementerio Poniente ${ }^{8}$}

A la orilla del camino que va de Quillagua a la costa. Aquí las sepulturas son superficiales y contienen pocos objetos fuera de las momias. Estas no obstante son bien acondicionadas y casi todas envueltas en tejidos, formando un atado mortuorio. Muchas de las momias ostentan una deformación levantada oblicua, pero otras tienen cráneos normales.

\footnotetext{
${ }^{8 /}$ Hoy en día este sitio se conoce con el código 02Qui03 (Gallardo et al. 1993a, 1993b).
} 


\section{Cementerio Oriente ${ }^{9}$}

Situado encima del cerro, a poca distancia al sureste de la estación del ferrocarril.

En este cementerio las sepulturas son muy numerosas y a pesar de haber sido saqueado, pudimos encontrar una veintena sin abrir. Tienen una profundidad mayor que las de los otros cementerios examinados llegando la mayoría de ellos a $2 \mathrm{mt}$ o más. Aquí se halló mayor número de objetos enterrados. Los tejidos eran más finos, muchos de ellos de vivos colores y con listas de hermosos dibujos. Hallamos una serie de gorros felpudos otros de un tejido que parece al crochet moderno y otros aún de junquillo con dibujos en colores. Los tejidos más numerosos tenían formas de bolsas grandes y chicas, la mayoría de vivos colores. Algunos de los chicos estaban llenas de harina de maíz o algarroba. También se hallaron muchos canastos de junquillos en forma de platos, de botellas y uno grande que parece campana. Ollitas y cántaros de greda se hallaron algunos intactos, pero la mayor parte de estos artefactos estaban fragmentados. Objetos de madera eran relativamente escasos pero se hallaron algunas tabletas y tubos para aspirar rapé [Figura 3] y algunas cajitas que habían sido utilizadas para guardar pinturas y para aparejos. Artefactos de hueso eran también escasos, pero entre los que se hallaron habían punzones, espátulas y tubitos.

Objetos de cobre se hallaron pocos, una pala, un anzuelo y un hacha. Encontramos también varias agujas fabricadas de espinas de quisco y varias madejas de lana de llama y de vicuña hiladas, como también una serie de husos de palos con sus torteras de madera. En una de las sepulturas se halló un arco en perfecto estado con su cuerda

\section{[Página 7]}

intacta, un carcaj de cuero de llama nueva, con varias flechas, una coraza hecha de cuero de cogote de llama [Figura 4]. En otra sepultura se hallaron unos trozos de cueros que evidentemente se habían destinado al mismo objeto. Hallamos dos arcos más algunos cuernos o puntas de otros pero no en el mismo estado perfecto como el primero. Las flechas eran numerosas pero en su mayoría faltaban las cabezas o puntas. Hallamos algunas de estas sueltas. Entre otras cosas aparecieron puntas de harpones [Figura 5], anzuelos y pesas para las lienzas de pescar.

Con frecuencia se hallan calabazas enteras o quebradas en su mayor parte lisas y sin adorno pero ocasionalmente pirograbadas. Conchas de choros también aparecen de vez en cuando y en casi todas las sepulturas trozos de pescado seis [sic] que parecen de jurel.

En casi todas las sepulturas encontramos mazorcas de maíz morocho o bien sus corontas. De vez en cuando también hallamos semillas de quinua, pero parece que el principal alimento era la algarroba y el maíz, que no faltaban en ninguna tumba. También aparecieron en este cementerio, algunos collares de silicato de cobre y otros de forma muy extraña compuestos por trozos irregulares y sin labrar de yeso, perforados en sus extremos y unidos por hilos de lana ${ }^{10}$. Aún cuando estos llevan la forma de collares, su peso y su tosquedad hacen creer que tal vez han servido para otro propósito, aún cuando es difícil adivinar cual ha sido.

Algunos de los platos y fuentes de greda, habiéndose trizado se remendaban haciendo perforaciones en ambos bordes de la trizadura y cociéndolas con hilo de lana o fibras vegetales. Se encontraron algunos capachos [Figura 4], hechos de palo cubiertos de estera o de un tejido suelto de junquillo como red. Es evidente que estos la llevaban en las espaldas por cuanto, en un caso hallamos la faja que lo sostenía.

\footnotetext{
9/ Hoy en día este sitio se conoce con el código 02Qui01 (Gallardo et al. 1993a, 1993b).

${ }^{10 /}$ Estos singulares objetos han sido descritos en detalle por Carlos Carrasco $(2001,2002)$ en los sitios de Quillagua.
} 


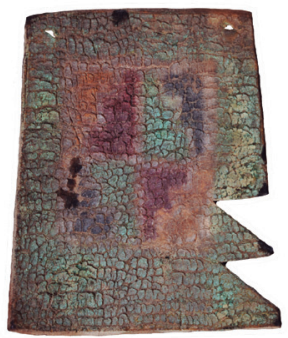

A

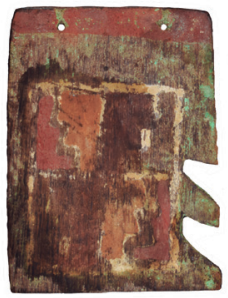

B
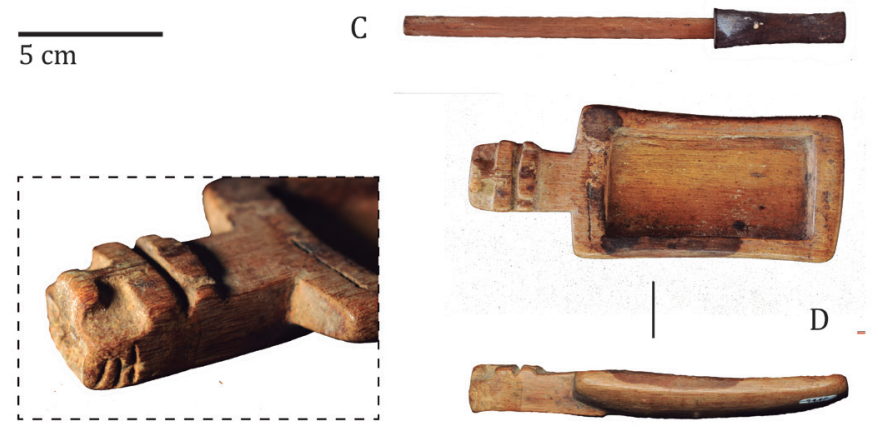

Figura 3: Objetos de la colección Latcham de Quillagua del MNHN: (A) placa de cuero decorada con figuras geométricas en colores verde, rojo, amarillo, negro y blanco ( $\mathrm{N}^{\circ}$ Inv. 9474); (B) pieza de madera decorada con figuras geométricas en colores verde, rojo, amarillo, negro y blanco ( $\mathrm{N}^{\circ}$ Inv. 9473); (C) tubo de madera con nariguera ( $\mathrm{N}^{\circ}$ Inv. 9402); (D) tableta de madera decorada ( $\mathrm{N}^{\circ}$ Inv. 9457).

Los indios vestían camisa sujeta en la cintura con una faja de lana. Generalmente las camisas se formaban de un tejido de unos dos metros de largo o un poco más con una abertura dejada en el centro por donde pasaban los brazos. No obstante algunas había que tenían cortas mangas que formaban parte del mismo tejido. También habían otras cortadas de modo especial, muy semejantes a las que hoy se usan y con escote tejidas de una sola pieza con costuras a los costados. Generalmente las camisas eran de un solo color, pero algunas habían con listas de color.

\section{[Página 8]}

Hombres y mujeres usaban el pelo largo, pero mientras los hombres lo llevaban suelto las mujeres usaban una infinidad de trenzas muy delgadas. A veces las trenzas eran más gruesas y anudadas sobre las sienes.

Tejían frazadas muy gruesas hechas de lanas en cordeles y también grandes mantas de abrigo que, sin embargo, no usaban como ponchos pues carecían de la abertura central, sino como rebosos. Calzaban chalalas u ojotas de cuero del cogote de llama y más raramente de cuero de lobo marino. En sus ceremonias usaban gorros bien confeccionados y de brillantes colores, generalmente de un tejido de lana de la contextura y apariencia de alfombra de Bruselas, felpudos exteriormente y lisos en el exterior [sic] también hacían gorros de pieles de aves con las plumas hacia afuera y a veces de pieles de animales. 
Las herramientas que usaban para la agricultura consistían de pitones o palos de algarrobo aguzados en un extremo en punta de cincel, palas de madera y de cobre, cuchillones de madera y palos de plantas.

Hacían cordeles de lana de las llamas y de las fibras de la cortadera o junquillo. Hacían redes de este mismo material. Pescaban con lienza y anzuelo y cazaban camarones, que se dan muy grandes en el río, con harpones de la misma manera como lo hacen los actuales habitantes. Es posible que también usaban trampas para cazar estos crustáceos como se hace en la actualidad. Para armar las trampas hacen una represa en el río, con estacas y ramas de algarrobo y céspedes, dejando una abertura en un lado donde ponen la trampa formada de un cono truncado de ramas entretejidas (hoy la hacen de alambre) en el cual quedan aprisionados los camarones arrastrados por la corriente.

Lo que extraña es que en estos cementerios, no se encuentran otros instrumentos de piedra que las puntas de flecha y de arpón. No se hallan ni hachas ni raspadores, ni buriles como en otras partes. Parece que antes de su radicación en Quillagua deben haber conocido el uso del cobre y bronce, aunque encontramos muy pocos objetos de metal.

Alfarería. Hay de dos clases, roja y negra y una que otra pieza de amarillo anaranjado. En tamaño varían mucho desde ollitas de pocos centímetros hasta ollas y cántaros de 50 a $60 \mathrm{~cm}$.

\section{[Página 9]}

En general, la alfarería es de paredes delgadas y esto explica el enorme número de fragmentos que se hallan en todos los cementerios. Las formas son muy variadas, siendo las más comunes los platos y las ollas de boca no muy ancha y vuelta hacia afuera.
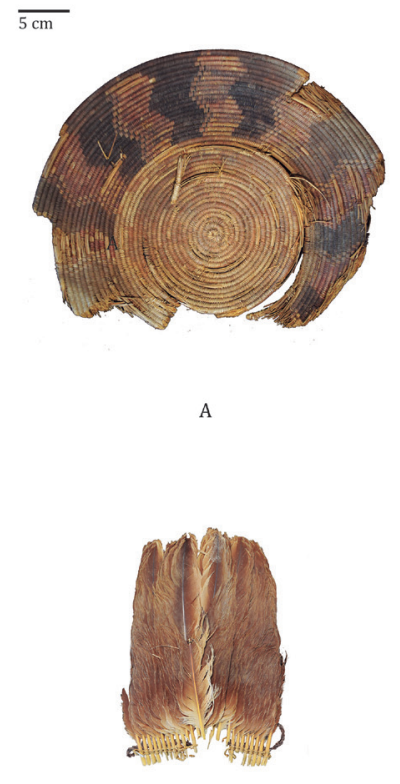

D

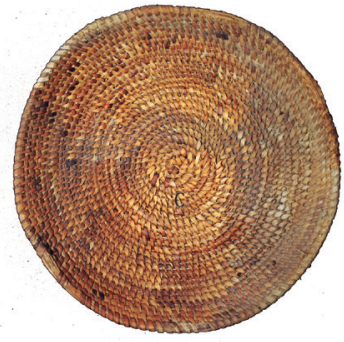

B

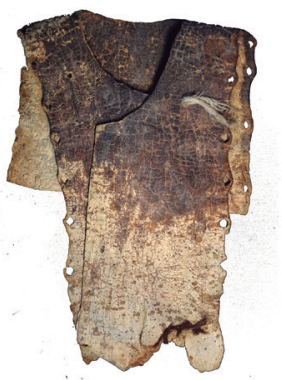

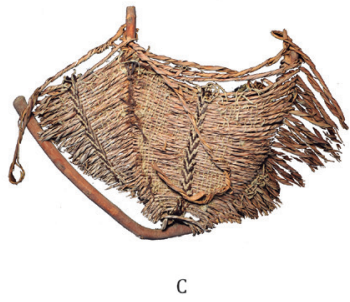

C

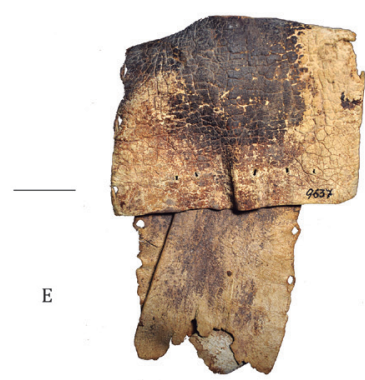

Figura 4: Objetos de la colección Latcham de Quillagua del MNHN: (A) cesto decorado con motivos geométricos ( $\mathrm{N}^{\circ}$ Inv. 9576); (B) cesto sin decoración ( $\mathrm{N}^{\circ}$ Inv. 9592); (C) capacho de fibras vegetales ( $\mathrm{N}^{\circ}$ Inv. 9629); (D) diadema de plumas $\left(\mathrm{N}^{\circ}\right.$ Inv. 9686); (E) coraza o peto de cuero ( $\mathrm{N}^{\circ}$ Inv. 9637). 
$5 \mathrm{~cm}$

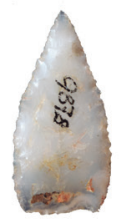

$\mathrm{B}$

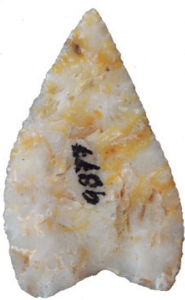

C

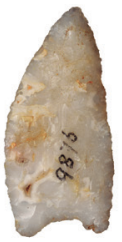

$\mathrm{D}$

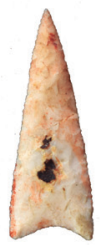

$\mathrm{E}$

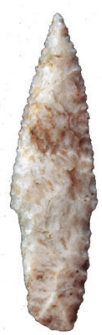

$\mathrm{F}$

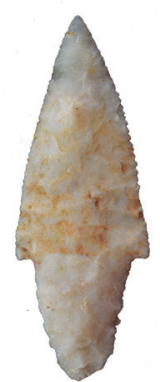

G
A

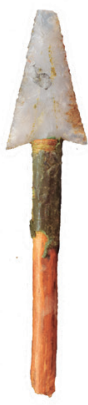

$\mathrm{H}$

Figura 5: Objetos de la Colección Latcham de Quillagua del MNHN: (A) cabezal de arpón tipo A con barbas de cobre ( $\mathrm{N}^{\circ}$ Inv. 9567); (B) cabezal lítico de base recta ( $\mathrm{N}^{\circ}$ Inv. 9378); (C) cabezal lítico asimétrico, posiblemente de cuchillo ( ${ }^{\circ}$ Inv. 9877); (D) cabezal lítico asimétrico, posiblemente de cuchillo ( ${ }^{\circ}$ Inv. 9876); (E) cabezal lítico triangular de base cóncava ( $\mathrm{N}^{\circ}$ Inv. 9563); (F) cabezal lítico pedunculado ( $\mathrm{N}^{\circ}$ Inv. 9532); (G) cabezal lítico pedunculado ( $\mathrm{N}^{\circ}$ Inv. 9875); (H) fragmento de flecha o proyectil con su punta inserta, amarrada y adherida con una goma de color verde $\left(\mathrm{N}^{\circ}\right.$ Inv. 9880).

Las astas varían entre $3,5 \mathrm{~cm}$ y $48 \mathrm{~cm}$. con un promedio para 41 flechas enteras de $39,5 \mathrm{~cm}$. Las puntas de madera fluctúan entre 10 y $24,5 \mathrm{~cm}$.

De 54 flechas con sus puntas que existen en el museo, proceden de diferentes localidades del río Loa, sólo dos de hueso, ninguna de ellas tiene punta de piedra y las otras 52 tienen puntas de madera.

La más larga de ellas, una de las con punta de hueso, mide $60 \mathrm{~cm}$ de largo. Todas las demás son más cortas y fluctúan entre 54,5 y $47 \mathrm{~cm}$.

La parte gruesa del asta es la punta superior donde se fija la punta y la parte delgada es la que se coloca sobre la cuerda del arco. Algunas son del mismo espesor en todo el largo, grueso medio $7 \mathrm{~mm}$, sólo una alcanza a $10 \mathrm{~mm}$. La mayoría de las flechas no lleva más que dos plumas cortas $(3 \mathrm{a} 4 \mathrm{~cm})$ colocadas paralelas al eje del asta y a más o menos un centímetro de la base. Hay algunas que en vez de dos plumas llevan tres y entre éstas, dos, las más gruesas y a la vez las más largas que tienen tres plumas colocadas con una pequeña oblicuidad que les da la forma de hélice. Las puntas de estas dos flechas se componen de dos partes; una segunda sección de palo, más delgada que el asta y embutida en ella y una punta formada de la espina de 7 u $8 \mathrm{~cm}$ de largo, plana y delgada, cuyas dos orillas son finamente dentadas. Hay bastante abundancia en la costa del Pacífico. 


\section{[Página 10]}

Ambas son de Quillagua. Son espinas de la cola de la raya. Tienen las siguientes dimensiones:

$\begin{array}{ccc} & \mathrm{N}^{\circ} 1 & \mathrm{~N}^{\circ} 2 \\ \text { Largo del asta } & 48 \mathrm{~cm} & 47,8 \mathrm{~cm} \\ \text { Largo de la segunda sección } & 11 \mathrm{~cm} & 10 \mathrm{~cm} \\ \text { Largo de la punta } & 6 \mathrm{~cm} & 6,5 \mathrm{~cm} \\ \text { Largo de las plumas } & 5 \mathrm{~cm} & 5 \mathrm{~cm} \\ \text { Diámetro del asta } & 10 \mathrm{~mm} & 9 \mathrm{~mm}\end{array}$

La base de todas las flechas están envueltas con una finísima hebra de nervio, la que toma la punta inferior de la pluma. Hasta este punto, la hebra está enrollada en forma que cada hebra aprieta la anterior, pero, al llegar a la pluma las vueltas se abren, dejando un milímetro de espacio entre una y otra pasando entre los plumones. Al extremo superior de las plumas, el hilo se afianza.

[Lo que sigue se encuentra en la libreta unas hojas más adelante]

Pero no todas las plumas se sujetan de esta manera. Algunas y quizá el mayor número son apretadas solamente en su extremo inferior, por el hilito de nervio y están pegadas el asta por una goma o mastica y quedan tan firmemente pegadas como cuando se colocaron, a pesar de los siglos. En algunos casos se ha hecho una ranura angosta en la cual la pluma ha sido pegada con la misma mastica.

El otro extremo del asta donde ha sido ahuecado para recibir la punta, también se ha reforzado con vueltas de nervio y en el caso de tener la flecha una segunda sección esta también ha sufrido la misma operación. La escotadura en el extremo inferior del asta para recibir la cuerda del arco, tiene una profundidad de 4 a $5 \mathrm{~mm}$. De las cuatro aljabas o carcajes de cuero que hay en el Museo, dos son de Quillagua, uno vacío y el otro con 6 flechas, uno de Arica con 24 flechas y otro de Chiu Chiu con 10 flechas. Sólo este último tiene 10 pelos. Las flechas son todas del mismo tipo, como lo son las demás de otras partes diversas de la región.

De 47 puntas de madera 31 son simplemente palitos puntiagudos, catorce tienen puntas aplanadas en los dos últimos dos centímetros con recorte que les sirve de barba y las otras dos aplanadas con puntas romas, estas últimas son más gruesas.

\section{[Página 11]}

\section{El Gentilar ${ }^{11}$.}

A más menos un kilómetro al sur del actual pueblo donde el río hace una curva abrupta hacia el oriente y encima del barranco del río, se hallan las ruinas de un gentilar o pueblo indígena. El sitio ocupado por estas ruinas abarca un trecho de unos $150 \mathrm{mts}$ de largo por unos 50 de ancho.

Las ruinas consisten en una serie de muros y pircas de piedra y argamasa de greda revuelta con yeso. Con el tiempo dicha argamasa ha tomado la consistencia de piedra y difícilmente cede ante la barreta.

\footnotetext{
11/ Corresponde a la aldea de La Capilla (02Qui04) del Período Intermedio Tardío y Tardío (Cervellino y Téllez 1980; Gallardo et al. 1993a, 1993b; Núñez 1976).
} 
Los muros, en algunas partes intactos, no parecen haber tenido una altura mayor de un metro. La mayoría de los muros longitudinales son de piedra canteada y los transversales de pirca. Ambos sentados en argamasa. Parece haber sido una construcción comunal y continúa dividido en un gran número de cuartos contiguos. No se ve indicios de puertas. Los cuartos tenían una dimensión de más menos dos metros por tres.

Los muros tienen un espesor de más menos $40 \mathrm{~cm}$ y las pircas de $50 \mathrm{~cm}$. No se ve indicios de techumbre, pero a juzgar por la manera como techaban las sepulturas y los techos planos que se usan actualmente en el pueblo de Quillagua y contornos, es probable que sus moradas fueron techadas de la misma manera, con travesaños de algarrobo sobre los cuales se estiraban esteras de sorona, cañas o carrizo. La única manera como pueden haber entrado en estas habitaciones ha sido indudablemente caminando por los muros y pircas. En ningún caso pueden haberse parado en sus casitas, ni aún los niños de modo que es probable que solamente servían de ellas para dormir, entrando por un claro en el techo.

Es de suponer que construían ramadas donde pasaban el día y hacían su cocina, guareciéndose de los vientos helados que aún en verano soplan de noche tras los muros de sus casitas. En las inmediaciones de estas construcciones al lado de la línea férrea existe al pie del cerro, un cementerio de donde abrimos las sepulturas asignadas con los $\mathrm{N}^{\circ} 1$ al 9 .

Según los restos de comida hallados en varias de las sepulturas, la alimentación de los indígenas de Quillagua era principalmente vegetal-maíz, quinua y algarrobo formaban las más comunes de los elementos. Traían pescado seco y mariscos también secos de la costa. En numerosas sepulturas hallamos jureles enteros y en fragmentos,

\section{[Página 12]}

abiertos por la mitad, en la misma forma que el bacalao entero que hoy se vende en el comercio ${ }^{12}$. Los principales mariscos cuyas conchas se hallan son los choros, lapas y locos.

El maíz se preparaba de diferentes maneras. Hallamos mazorcas enteras, maíz desgranado, harina de maíz, tortas o tortillas, mazamorra, en platillos, en bolsitas y en ollitas [Figura 2]. En una olla de greda de regular tamaño hallamos maíz reventado pululo que en el sur se llama llalli (popped corn) tan blanco y tan entero que parecía recién hecho [Figura 2].

La algarroba la hallamos entera, molida en harina y en pasta o torta. La quinua solamente la hallamos en forma de semilla. Es de la variedad negra y no hallamos la cenicienta. Es de suponer que también comían ocasionalmente la carne de llama y en dos ocasiones hallamos momias de estos animales dentro de las sepulturas. Es también indudable que comían los camarones que es una especialidad del río Loa en este lugar donde abundan y crecen a un tamaño desconocido en otras partes.

Otros productos vegetales como el poroto, el zapallo, las calabazas, las papas y las frutas de todas clases no se dan en el valle debido al agua salobre, pero es posible que las traían de Huatacondo, Pica y otros valles cordilleranos como hacen en la actualidad.

Deben también haber cazado las avecitas que frecuentan el valle, como la loica, el pidén, la tagua, el

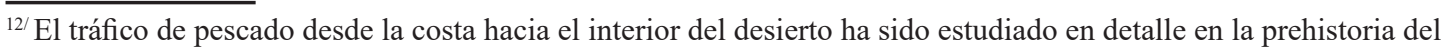
desierto de Atacama y también del valle de Quillagua, donde habría estado funcionando al menos desde el período Formativo (Ballester et al. 2019b).
} 
pato silvestre y quizá otras, porque se hallan numerosas flechas pequeñas y delgadas con puntas de madera o de piedra que solamente podrían haber servido para la caza de aves.

La mayor parte de las flechas son hechas de tallos de sorona o chilca ahuecados en el extremo superior donde se han extraído la médula para dar cabida a las puntas de madera dura.

\section{Cráneos.}

En este cementerio encontramos un nuevo tipo de deformación. Esta era levantada, pero no oblicua como en el cementerio poniente. Estos cráneos tienen la frente más o menos achatada, echada hacia atrás, pero el occipital también a veces fuertemente aplanado, cae rectamente y no hacia atrás como en los anteriores.

En las 50 sepulturas abiertas, solamente encontramos 2 momias con deformación oblicua y 15 con cráneos normales. Todos los demás eran derechos con la frente echada hacia atrás. Los cráneos normales eran braquicéfalos con tendencia hacia la sub-braquicefalia.

\section{[Página 13]}

\section{Cementerio Poniente ${ }^{13}$.}

Cadáveres encogidos. En las sepulturas más antiguas casi todos desnudos. En otras, envueltos en grandes telas de lana y amarradas con cordeles de fibras vegetales. Muy pocos objetos.

Alfarería tosca doméstica.

Puntas de flecha.

Maíz.

Gorros de pieles.

Canastos en forma de platos.

Nada de metal.

Faltaban objetos de madera probablemente destruidos por el tiempo

\section{Cementerio oriente ${ }^{14}$}

Falda. Atacameño

\section{Cima. Chincha Atacameño}

\footnotetext{
13/ Hoy en día este sitio se conoce con el código 02Qui03 (Gallardo et al. 1993a, 1993b).

${ }^{14 /}$ Hoy en día este sitio se conoce con el código 02Qui01 (Gallardo et al. 1993a, 1993b).
} 
Caur-caure-cauri= cerro en atacameño

No existe la voz en quechua ni en aimará.

Licancaur, Tinticaur, Caurichari, Tomecaure.

Toco, Tokko= cueva, alacena. La palabra quechua que corresponde a tocco es tampu. P.177 Incas

Tookor o Tokkor $=$ foso

Tokol $=$ profundo

Tokomar $=$ gusano

Esta voz tampoco existe en quechua ni en aimará.

Toco, Tocopilla, Toconce, Tocore, Tocotocaure, Tocotor, Tocorpuri, Toconao, Tococo.

En la Puna de Atacama y en la Puna de Jujuy las cuevas o grutas sepulcrales usadas por los antiguos indios atacameños, todavía se llaman, o se llamaban hace 50 años tocco o tokko.

Esta voz fue adoptada en la lengua quechua, primero para hablar de las cuevas funerarias y luego para significar alacena o nicho.

La ventana o nicho que perforaba completamente el muro era una innovación del último periodo incaico y por extensión la voz toco, llegó a adquirir el sentido de "ventana". Los cronistas españoles fueron los que aplicaron el término tanto a los nichos como a las aberturas perforadas de los muros pero en verdad corresponde a hueso, nicho, alacena, o más propiamente a cueva o gruta.

Incas p.178 nota

\section{[Página 14]}

Tótems de los Incas proporcionados por Sarmiento de Gamboa. (Incas p.119 y sig.). Chuqui Illa o Inti Illapa tótem del inca Yupanqui Pachacuti (Incas p.522) véase nota.

Nota: Chuqui-lanza, Illa-luz.

Creencias. p.162, nota p. 172

pp. $167-170,220-224$

Urleaga (El Imperio Incaico) p.154, dice:

"El tótem del ayllo Inca Panaca fue el Inti Illapa - el rayo y, seguramente, su símbolo la serpiente -amaro- como el de sus antecesores inmediatos. 
El señor Cornely halló en el Olivar ${ }^{15}$, cerca de La Serena, espátulas de hueso grabadas con tigres, iguales a las encontradas en Caldera y Taltal, lo que parece demostrar que este arte es Diaguita y no Atacameño. Las tres que vi eran idénticas con las que existen en el Museo. Las torteras elípticas con circulitos negros son también iguales a las de Caldera y Taltal.

Las puntas de arpón del Arrayán al norte de La Serena son también iguales a las de Taltal. En el Olivar se encuentran dos culturas superpuestas que corresponden a las épocas atacameña indígena y la Chincha atacameña de más al norte. Yo las llamo Diaguita y Chincha Diaguita.

La alfarería de la primera es de dibujos grandes muy distintos a los menudos del segundo período y se encuentran entre ellos muy repetida una figura con base triangular con ramificaciones que los hacen parecer peines. También se encuentra entre los elementos decorativos del interior de los platos la cruz con los triángulos interiores dejados por los trazos rellenos de dibujos diversos rectilíneos.

También era común a esta cultura vasos asimétricos con rollos superpuestos, rayados como en los jarros patos y con una cara en un lado, hecha de los ojos y boca en relieve, y ollas altas con las mismas caras.

[Fin del manuscrito]

\section{AGRADECIMIENTOS}

ANID-FONDECYT 1210046. Se agradece al Museo Nacional de Historia Natural por el apoyo y acceso a sus archivos administrativos, con los cuales fue posible la publicación de este texto.

\section{REFERENCIAS BIBLIOGRÁFICAS}

AGÜERO, C. 1998. Tradiciones textiles de Atacama y Tarapacá presentes en Quillagua durante el período Intermedio Tardío. Boletín del Comité Nacional de Conservación Textil 3: 103-128.

AGÜERO, C. 2015. Vestuario y sociedad andina. Desarrollo del Complejo Pica-Tarapacá (800-1400 DC). Qillqa Ediciones, Santiago.

AGÜERO, C. y B. CASES. 2004. Quillagua y los textiles Formativos del Norte Grande de Chile. Chungara, Revista de Antropología Chilena Volumen Especial: 599-617.

AGÜERO, C., M. URIBE y O. REYES. 1995. Nuevos sitios para la ocupación formativa del valle de Quillagua. Boletín de la Sociedad Chilena de Arqueología 21: 24-27.

AGÜERO, C., M. URIBE, P. AYALA y B. CASES. 1997. Variabilidad textil durante el Período Intermedio tardío en el valle de Quillagua: Una aproximación a la etnicidad. Estudios Atacameños 14:263-290.

AGÜERO, C. M. URIBE, P. AYALA y B. CASES. 1999. Una aproximación arqueológica a la etnicidad y el rol de los textiles en la construcción de la identidad cultural en los cementerios de Quillagua, norte de Chile. Gaceta Arqueológica Andina 25: 167-197

AGÜERO C., M. URIBE, P. AYALA, B. CASES y C. CARRASCO. 2001. Ceremonialismo del periodo Formativo en Quillagua, Norte Grande de Chile. Boletín de la Sociedad Chilena de Arqueología 32: 24-34.

AGÜERO C., P. AYALA, M. URIBE, C. CARRASCO y B. CASES. 2006. El periodo formativo desde Quillagua, Loa inferior (norte de Chile), En Esferas de interacción prehistóricas y fronteras nacionales modernas: los Andes sur centrales, pp.73-118, editado por H. Lechtman, Instituto de Estudios Peruanos, Lima.

AICHEL, O.1932. Ergebnisse einer Forschungsreise nach Chile-Bolivien. Zeitschrift für Morphologie und Anthropologie 31(1):1-166.

AYALA, P. 2001. Las sociedades formativas del Altiplano Circumtiticaca y Meridional y su relación con el Norte Grande de Chile. Estudios Atacameños 21: 7-39.

${ }^{15}$ El sitio El Olivar fue excavado por primera vez por Samuel Lothrop en 1929 y luego por Francisco Cornely (1936). Es posible que la referencia a los trabajos de Cornely en El Olivar se deba a una anotación posterior de Latcham a la transcripción de las notas del viaje a Quillagua, con fines de análisis y comparación. 
BALLESTER, B. 2021a. Arpones precolombinos de Antofagasta. Acople de partes, collage de materiales, ensamblaje de seres y mosaico de paisajes. En: Ensamblajes del pasado. Lugares, objetos y reflexiones, pp. 99-136, editado por D. Quiroz. Ediciones de la Subdirección de Investigación, Santiago.

BALLESTER, B. 2021b. Biografía de una colección y su coleccionista: Los vestigios de Aníbal Echeverría y Reyes en el Museo Nacional de Historia Natural de Santiago. Bajo la Lupa, Subdirección de Investigación, Servicio Nacional del Patrimonio Cultural.

BALLESTER, B., D. HERNÁNDEZ y C. CHÁVEZ. 2019a. Arqueología de archivos y archivos para la arqueología. Colección Schwenn del Museum am Rothenbaum (MARKK) de Alemania. Revista de Arqueología Americana 37:4374.

BALlester, B., E. CALÁs, R. LABARCA, W. PeSTle, F. GAlLARDO, C. CASTILlo, G. Pimentel y C. OYARZO. 2019b. The ways of fish beyond the sea: The circulation and consumption of fish in the Atacama Desert during the Formative period. Anthropozoologica 54(6):55-76.

CARMONA, J. 2018. Alfalfa y minería en el desierto surandino. Revista Chilena de Antropología 37:213-229.

CARRASCO, C. 2001. Industria lítica para sitios rituales en Quillagua, II región. Boletín de la Sociedad Chilena de Arqueología 31: 26-32.

CARRASCO, C. 2002. Las industrias líticas de Quillagua durante el período Formativo, en el contexto del Norte Grande. Estudios Atacameños 22: 33-57.

CARRASCO, C., C. AGÜERO, P. AYALA, M. URIBE y B. CASES. 2003. Investigaciones en Quillagua: Difusión del conocimiento arqueológico y protección del patrimonio cultural. Chungara, Revista de Antropología Chilena 35(2):321-326.

CASES, B. 2003. Continuidad y cambio en las bolsas domésticas. Boletín de la Sociedad Chilena de Arqueología 35/36: 28-46.

CASES, B. 2007. Continuidad, cambio y variaciones en las bolsas domésticas de Quillagua durante el Período Intermedio Tardío. Tesis para optar al grado de Magister en Antropología, Universidad Católica del Norte y Universidad de Tarapacá, Santiago.

CASES, B. e I. MONTT. 2013. Las túnicas rupestres pintadas de la cuenca media y alta del Loa vistas desde Quillagua (norte de Chile). Chungara, Revista de Antropología Chilena 45(2): 249-275.

CERVELLINO, M. y F. TÉLLEZ. 1980. Emergencia y desarrollo en una Aldea Prehispánica de Quillagua-Antofagasta. Contribución Arqueológica 1: 1-235

CORNELY, F. 1936. El cementerio indígena de El Olivar. Boletín del Museo Nacional de Historia Natural 15:35-39.

CORREA, J. 1998. Descripción y análisis de diseño de los tejidos del Cementerio Oriente del valle de Quillagua, II Región. Boletín del Comité Nacional de Conservación Textil 3: 129-144.

DE LA BARRA, F. 1909. Sobre dos momias procedentes de Quillagua. Revista Chilena de Historia Natural 13(6): 333-336.

DIEHL, D. 1904. An bord und im sattel. Moritz Schauenburg, Leinen.

FONCK, F. 1911. Les crânes à parois épaisses selon Vergara Flores. Avec une documentation supplémentaire sur le crâne des pêcheurs des régions australes. Le crâne de Mechi et les causes de l'épaississement des parois crâniennes. Bulletins et Mémoires de la Société d'Anthropologie de Paris 2: 135-155.

FONCK, F. 1912. Los cráneos de paredes gruesas según L. Vergara Flores, con unos datos más. Revista Chilena de Historia y Geografía 7: 311-345.

GALLARDO, F. 2019. El oasis de Quillagua, la frontera interior: Tres siglos de arqueología (Desierto de Atacama, norte de Chile). Qillqa Ediciones, Santiago.

GALLARDO, F. y M. ODONE. 2019. El oasis de Quillagua: una nota sobre fronteras entre Picas y Atacamas. Antropologías del Sur 12: 175-187.

GALLARDO, F, L. CORNEJO, R. SÁNCHEZ, B. CASES, A. ROMÁN y A. DEJA. 1993a. Una aproximación a la cronología y el asentamiento en el oasis de Quillagua (Río Loa II región). Actas del XII Congreso Nacional de Arqueología Chilena. Tomo II, pp. 41-60. Museo Regional de la Araucanía, Temuco.

GALLARDO, F, L. CORNEJO, R. SÁNCHEZ, B. CASES, A. ROMÁN y A. DEJA. 1993b. Arqueología en el valle de Quillagua, río Loa, Norte de Chile. Gaceta Arqueológica Andina 23: 125-138. 
GALLARDO, F., C. AGÜERO, M. URIBE y G. PIMENTEL. 2019. Quillagua: las categorías del encuentro cultural y sus desplazamientos desde el siglo XIX hasta la actualidad. En El Oasis de Quillagua, la frontera interior: tres siglos de arqueología (Desierto de Atacama, norte de Chile), pp. 21-26, editado por F. Gallardo. Qillqa Ediciones, San Pedro de Atacama.

GARCÍA, M., E. VIDAL, C. LEMP, E. SCHAEFFER, F. SANTANA y T. PARDO. 2012. Rescate y puesta en calor del cementerio Rinconada de Quillagua. En: Actas del XVIII Congreso Nacional de Arqueología Chilena, pp. 131-140. Sociedad Chilena de Arqueología, Santiago.

LATCHAM, R. 1910. Los changos de las costas de Chile. Imprenta Cervantes, Santiago.

LATCHAM, R. 1912. Los cráneos de paredes gruesas. Revista Chilena de Historia y Geografía 7: 346-358.

LATCHAM, R. 1933. Notas preliminares de un viaje arqueológico a Quillagua. Revista Chilena de Historia Natural 37: 130-138.

LATCHAM, R. 1938. Arqueología de la Región Atacameña. Prensas de la Universidad de Chile, Santiago.

LATCHAM, R. 1969. Exploraciones de túmulos de la Punta Teatinos, Prov. Coquimbo. Noticiario Mensual del Museo Nacional de Historia Natural 152: 3-6.

MÉNDEZ-QUIROZ, P. y E. VIDAL. 2010. Reparación del saqueo de un cementerio indígena en el Norte de Chile. Quillagua Oriente, Región de Antofagasta. En Primer Congreso Iberoamericano sobre Patrimonio Cultural, pp. 26782697. Universidad de Costa Rica, San José.

NÚÑEZ, L. 1965a. Prospección arqueológica en el norte de Chile. Estudios Arqueológicos 1: 9-36.

NÚÑEZ, L. 1965b. Desarrollo cultural prehispánico del norte de Chile. Estudios Arqueológicos 1: 37-85.

NÚÑEZ, L. 1976. Registro regional de fechas radiocarbónicas del norte de Chile. Estudios Atacameños (4): 69-111.

ODONE, M. 1995. Quillagua: la Descripción de un Espacio desde la Historia. En Actas del II Congreso Chileno de Antropología, Vol. 2, pp. 598-605. Colegio de Antropólogos de Chile, Valdivia.

ODONE, M. 2017. El valle de Quillagua (siglos XVI-XX). Palimpsesto NE: 120-150.

PESTlE. W., C. TORRES-ROUFF, F. GALlARDO, G. CABELlO, E. SMITH y A. CLAROT. 2019. The interior frontier: Exchange and interculturation in the Formative period (1000 B.C.-A.D. 400) of Quillagua, Antofagasta region, northern Chile. Quaternary International 533: 25-36.

PIMENTEL, G. y I. MONTT. 2008. Tarapacá en Atacama. Arte rupestre y relaciones intersocietales entre el 900 y 1450 DC. Boletín del Museo Chileno de Arte Precolombino 13(1): 35-50.

PINDER, D., F. GALLARDO, G. CABELLO, C. TORRES-ROUFF y W. PESTLE. 2019. An isotopic study of dietary diversity in formative period Ancachi/Quillagua, Atacama Desert, northern Chile. American Journal of Physical Anthropology 170(4): 613-621.

PUSCH, S. 1988. A grave group from Quillagua, Northern Chile. Unpublished undergraduate dissertation, Institute of Archaeology, UCL, Londres.

SANTANA F., M. HUBBE y M. URIBE. 2015. Isotopic evidence for marine consumption and mobility in the Atacama Desert (Quillagua, northern Chile). International Journal of Osteoarchaeology. https://doi.org/10.1002/oa.2437

STRANGE, J. 1995. Cementerios saqueados en Quillagua. Museos 20: 21-24.

URIBE, M. y P. AYALA. 2004. La alfarería de Quillagua en el contexto Formativo del norte grande de Chile (1.000 a.C. - 500 d.C.). Chungara, Revista de Antropología Chilena 36(2): 585-597.

VERGARA, L. 1897. Piedras escritas de Quillagua. En Actas del IV Congreso Científico Jeneral Chileno, pp. $354-364$. Talca.

VERGARA, L. 1901. Nuevas mediciones en trece cráneos antiguos de Aimaráes (huacas de Quillagua). Revista Chilena de Historia Natural 5(5/6): 125-136.

VERGARA, L. 1902. Estudio comparativo sobre cráneos araucanos i antiguos aimaraes. Revista Chilena de Historia Natural 6(4): 197-217.

VERGARA, L. 1905. Cráneos de paredes gruesas (nuevas investigaciones en 63 cráneos de Quillagua y algunos de la costa). Revista Chilena de Historia Natural 9(1): 172-190. 